HUNGARIAN AGRICULTURAL ENGINEERING

$N^{\circ} 27 / 201531-34$

Published online: http://hae-journals.org/

HU ISSN 0864-7410 (Print) / HU ISSN 2415-9751(Online)

DOI: 10.17676/HAE.2015.27.31
PERIODICAL OF THE COMITTEE OF AGRICULTURAL AND BIOSYSTEM ENGINEERING OF

THE HUNGARIAN ACADEMY OF SCIENCES and

SZENT ISTVÁN UNIVERSITY

Faculty of Mechanical Engineering

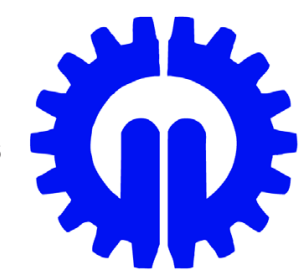

\title{
REALIZATION THE VOLUMETRIC FLOW CONTROL OF A DOMESTIC SIZE SOLAR COLLECTOR SYSTEM
}

\author{
Author(s): \\ I. Seres - P. Víg
}

Affiliation:

Department of Physics and Process Control, Szent István University, Páter K. street. 1., Gödöllö, H-2100, Hungary

Email address:

seres.istvan@gek.szie.hu, vig.piroska@gek.szie.hu

\begin{abstract}
The efficiency of the solar systems is influenced by numerous factors, and the control of the system is an important one among them. The usage of the flow control of solar liquid by influencing the rotational speed of the pump by a frequency controller has several advantages compared to the simple on-off switch regulation. To investigate these advantages the control system of a domestic size solar hot water system was changed this way in the Department of Physics and Process Control, Szent István University. In the paper the realization of the control is presented (installation, parameter setting of the used Altivar frequency inverter). The operation of the Labview control routine is described as well.
\end{abstract}

\section{Keywords}

solar energy, control, frequency regulation, efficiency, transient

\section{Introduction}

The first experiments with the solar applications started about 20 years before in the Department of Physics and Process Control, Szent István University, Gödöllö, Hungary, and since then a wide range of experimental equipment was installed for the different projects in the Department. Among them three type of solar collector (flat plate, vacuum tube and $\mathrm{PV} / \mathrm{T}$ - hybrid photovoltaic and solar thermal) collects the heat for a domestic size hot water system, beside them a domestic size solar dryer, a transparent insulation wall and a $1 \mathrm{kWp}$ photovoltaic system consist of the basics of the Department system.

At the University campus, there are some more, bigger units, operated by our Department staff, e.g. a $10 \mathrm{kWp}$ grid connected photovoltaic system, a solar thermal system for heating the water of the swimming pool, and another one for the greenhouses of the horticulture unit of the University, a smaller, domestic size hot water system in the building of the experimental laboratories with vacuum tube collectors. The control of the mentioned systems are solved by computer based data logging systems, however we operate a few independent one.

\section{The investigated system}

The thermal units

The present paper is dealing with the household size hot water system, working at the Department. During the measurements this system was operated by a vacuum tube collector ( 15 heat pipe technology tubes), which is installed at the terrace of the department. The collector is oriented to South and it has an inclination angle of $45^{\circ}$ to the horizontal (the inclination angle can be adjusted for several values as a seasonal optimum, but these measurement results were achieved by this value). The picture of the collector can be seen in Figure 1.

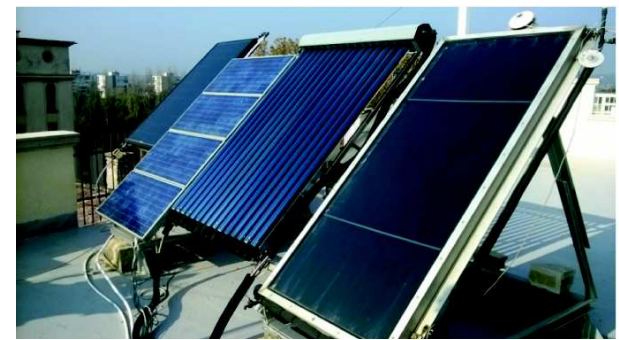

Figure 1. Solar collectors at the department, among them the vacuum tube collector $\left(2^{\text {nd }}\right)$, used or the experiments
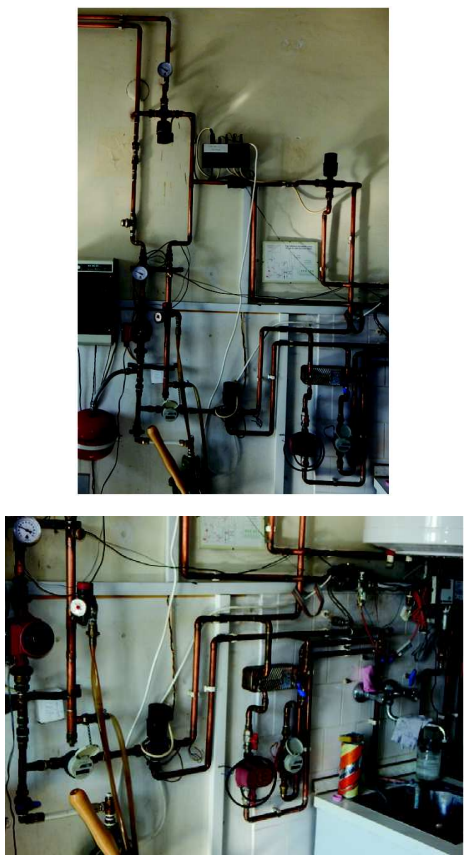

Figure 2. The tube and valve system inside the research laboratory 
The collector is connected to the inner units and the hot water tank by partly insulated $20 \mathrm{~mm}$ diameter copper tubes. As the research laboratory is relatively far from the terrace (location of the collectors), a relatively long (approximately $50 \mathrm{~m}=2 \cdot 25 \mathrm{~m}$ ) tube system connects the collectors to the hot water tank. Inside the laboratory a relatively complicated valve system (Figure 2.) makes possible to route the hot water to the storage tank or to an experimental greenhouse scale-model (for heating its soil). There is an alternative possibility to circulate back the liquid to the outgoing tube if its temperature is not warm enough.

The storage tank is a 300 liter capacity, insulated tank $(5 \mathrm{~cm}$ insulation) with double heat exchanger inside. The collector was connected to the heat exchanger located in the bottom part of the tank, the useful area of the heat exchange is $1 \mathrm{~m} 2$. In Figure 3 the storage tank and its schematic figure can be seen.

Figure 3. The photo and the schematic figure of the solar tank (3 temperature measuring points)

\section{The data logging / control system}

The data logging / controlling is realized by a PC based system. The system is set up by Adam data converter and communication units, which are communicate to each other and the computer by RS485 communication standard.

The used temperature sensors are partly Pt1000 Platinum thermal resistors (e.g. on the collectors in- and output sides, where high temperatures my occur), and partly NTC 10k thermal resistors (e.g. for the solar tank: top, middle, top, heat exchanger inlet and outlet point, fresh and hot water outlet point). The sensors are connected to the proper ADAM module (ADAM 4015 and ADAM 4015T), which modules send the data to the PC through an ADAM4060 RS485 communication module.

The communication software is an old development of an earlier member of the department staff, written in C, originally made for a win 95 system. Now a new version of the software is developed under Labview, only the communication of this software with the ADAM modules has to be solved yet. The measured data are saved to the hard drive of the data logger with the time period, determined by the users of the software (typically every $30 \mathrm{~s}$ ). The view of the screen during the data logging can be seen in Figure 4 [1].

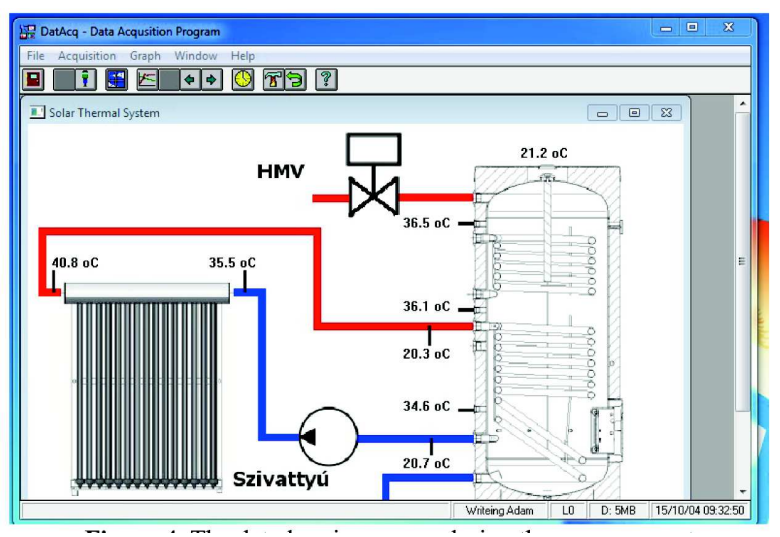

Figure 4. The data logging screen during the measurement

The used control method by the software the On-Off switch method was, such as the software was switching on or off the pump (through a relay) depending on the tank temperature is higher by 5 degree then the collector output or not.

\section{The measured data, inducing the change}

From the analysis of the measured data the next problem can be recognized. When the incoming solar power was not strong enough to maintain a stable temperature difference, bigger than the mentioned 5 Celsius between the collector output and the middle layer temperature of the storage tank, a continuous on-off switching could be seen in the system (Figure 5.). This state can occur during the morning, evening or partly cloudy conditions.
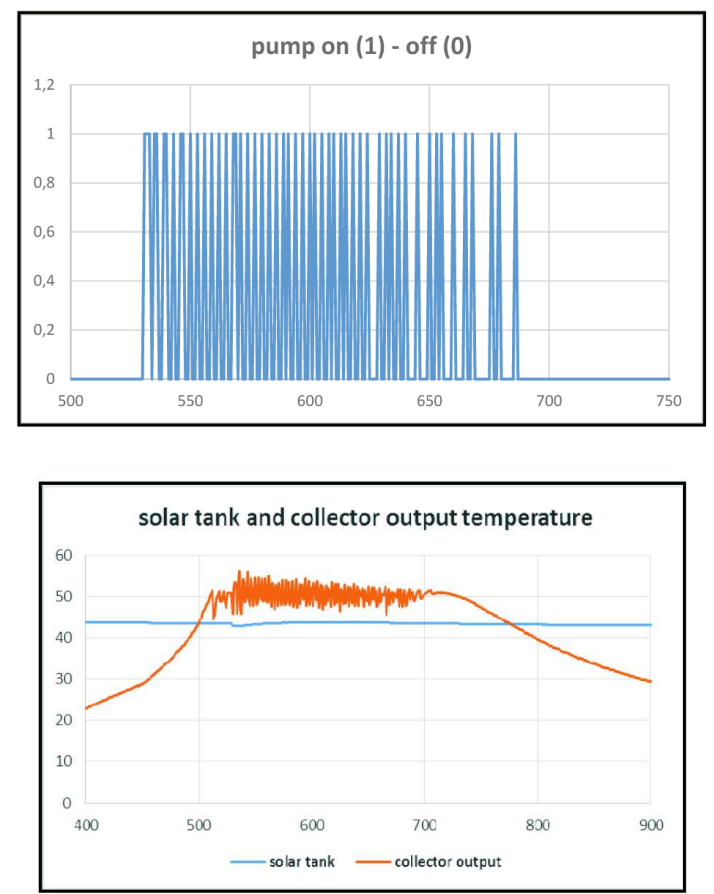

Figure 5. The data logging result in a cloudy day (2015 07.13)

The problem with this continuous on-off switching is that as the tubes are very long, the hot water could not get into the tank, but it was cooled back inside the tubes dissipating the energy to the surroundings, and heating the building. This case was shown for cloudy conditions, but similar effects can be seen for the morning and late afternoon periods, as well.

\section{Modification of the control system for volmetric flow control}

The idea we wanted to check is the regulation of the rotational speed of the solar pump, and in this way the regulation of the solar liquid flow velocity, thus the regulation of the flow rate (volumetric current) of the heat transporting medium. To achieve this first a simple lamp switch regulator (based on phase cut) was installed to the system, but with that the pump did not worked well together.

\section{The frequency controller}

Thus later on an Altivar 31 (Figure 6.) frequency controller was installed to the system [2]. The main properties of the used device are as follows (beside a lot of not so important properties for us): - control range: 3 phase control in the range of $0-500 \mathrm{~Hz}$ - power range: $0,18 \mathrm{~kW}-2,8 \mathrm{~kW}$

-acceleration and deceleration ramp time : $3 \mathrm{~s}$ (default, can be adjusted)

At the beginning a few sets has to be adjusted, e.g: as we used only one phase, the phase control function had to be tilted (checking the other two phases is tilted), and the rotation direction of the vector had to be defined (forward), and finally the control method had to be set [3]. 


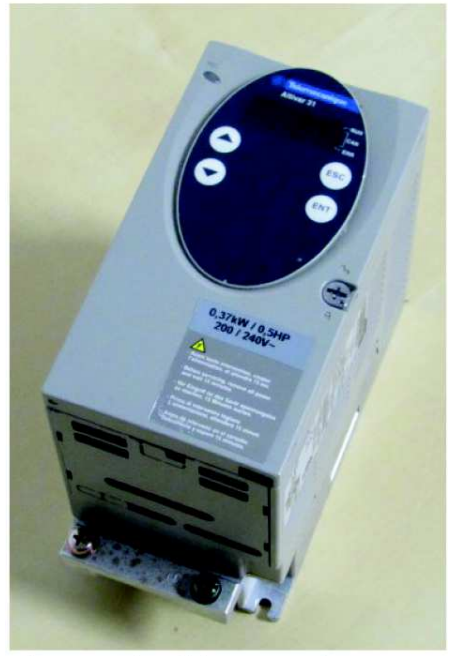

Figure 6. The used Altivar31 frequency regulator

To control the pump, there are different options, it is possible to choose between presets values (changeable factory defaults), or with analog input, $0-10 \mathrm{~V}$ analog voltage or 4-20 mA current input.

In our case the voltage input was chosen in the regulator, and as the used DA unit was in the output range of $0-5 \mathrm{~V}$, the high frequency, dedicated to the $10 \mathrm{~V}$ input was set to $100 \mathrm{~Hz}$. In this case, when $5 \mathrm{~V}$ of regulating voltage was sent to the unit, it was providing $50 \mathrm{~Hz}$ to the pump. In this way it was possible to regulate the frequency in the $0-50 \mathrm{~Hz}$ range, by the $0-5 \mathrm{~V}$ voltage interval.

\section{Generating the control voltage}

The next task was to generate the proper control voltage to the frequency regulator. As the necessary frequency is depending on the collector and tank temperatures measured by the computer, it was natural to use the data logging PC for this purpose. Theoretically there was an analog output voltage module installed in the data logging system, but it was used for different purpose.

As for data logging tasks different National Instruments hardware are in the department, as this task was quite simple, an USB6009 IO unit was used. It has two analog Input and output channels and 8 digital ones. For us the analog output was important, the output0 port was used for the task [4].

The physical setup of the USB6009 connected the frequency regulator can be seen in Figure 7 .

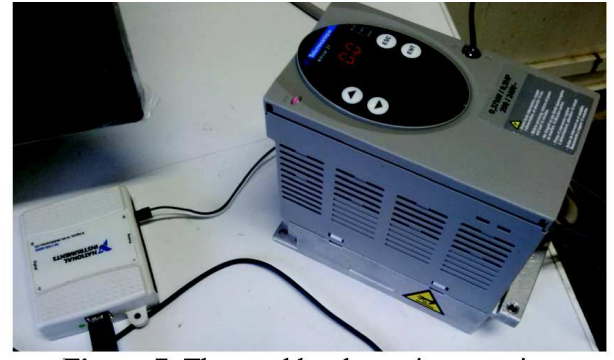

Figure $\overline{7}$. The used hardware in operation

The software background: Labview

As the $\mathrm{C \#}$ source code of the original data logging system was not available, a new routine had to be written for adjusting the proper voltage level of the USB6009 unit. To achieve this the Labview was used, from which the usage of the USB6009 is very simple [5].

The only problem had to be solved how to get the temperature data, measured by the old, $\mathrm{C \#}$ based data logging system. As the parameter change was practically impossible without the source code, a not so elegant, but working method was used. The data logging system was writing to the hard disk the measured parameters, and the Labview was reading them out. to use for the control voltage.

The first time the refresh rate of the important data was $30 \mathrm{~s}$, and the Labview was reading them back at the same rate, but as the two programs work independently, in some cases almost $60 \mathrm{~s}$ were the delay between the measurement and the voltage answer. For more fluent operation the refresh time was reduced to $10 \mathrm{~s}$.

As the control measurements showed, that the pump operation is in the range of $2,5 \mathrm{~V}-5 \mathrm{~V} / 25 \mathrm{~Hz}-50 \mathrm{~Hz}$ interval (below 2,5 $\mathrm{V} / 25 \mathrm{~Hz}$ the output power of the frequency inverter - which is changing by the frequency - was not enough to rotate the pump. So for the real control the $2,5 \mathrm{~V}-5 \mathrm{~V}$ voltage range was used.

As the frequency inverter made the voltage of $0-5 \mathrm{~V}$ to the frequency of $0-50 \mathrm{~Hz}$, and maximum rotation speed was planned if the temperature difference between the collector output and the solar tank is bigger than 5 Celsius, so the measured temperature difference was set as the control voltage for the frequency inverter, with the maximum value of $5 \mathrm{~V}$. (If the temperature difference went above 5 degree, the voltage was limited to $5 \mathrm{~V}$.)

However the measurement is going on 24 hours, the running of the control is reduced to the sonny intervals, the pump is shot down other time. The Labview code and the information screen during the operation can be seen in Figure 8.

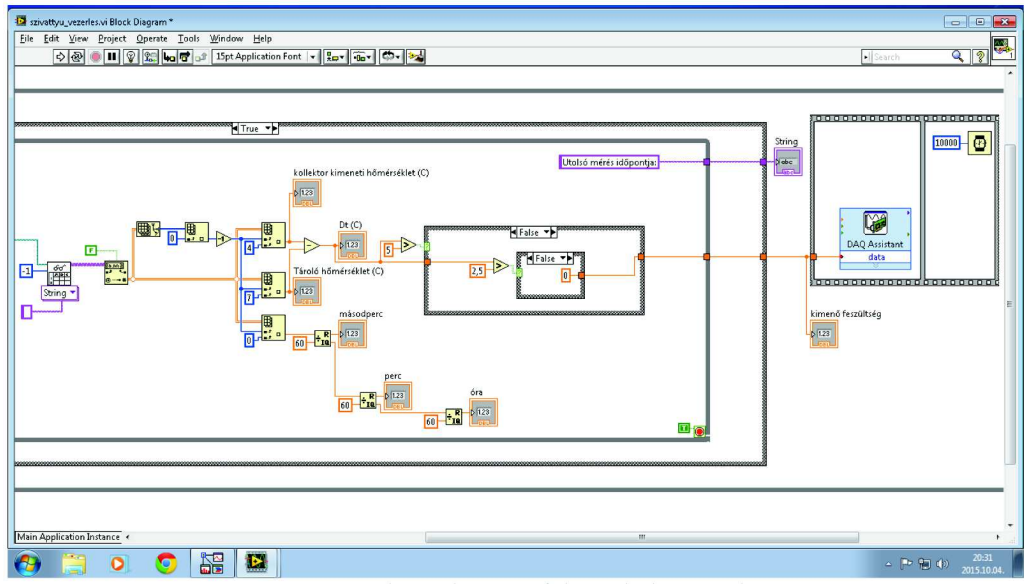

Figure 8. The code-part of the Labview routine 


\section{The effect of the modification}

As the effect of the system change, smoother operation of the pump was predicted, which was checked from the measured value. Compared to the up and down jumping functions of the
On-Off switch regulation, more smooth functions were expected. It was partly true (Figure 9.), however some more fine tuning in the morning and late afternoon should be done yet. The energetic consequences are shown in a separate paper.
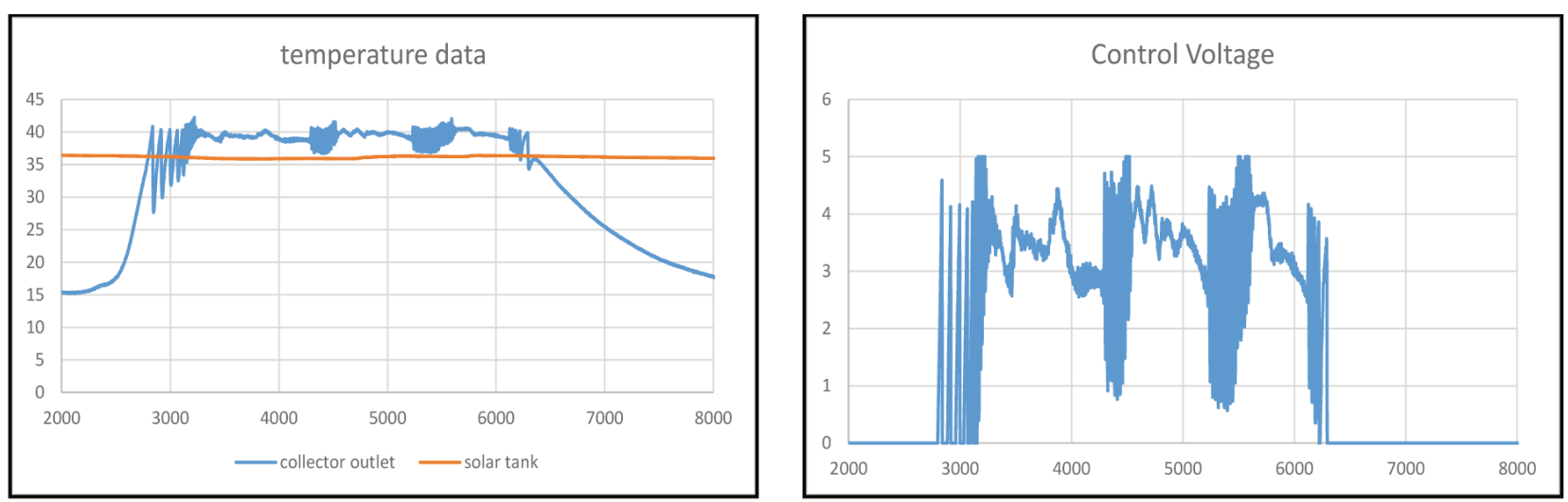

Figure 9. The temperature functions after the modification and the control voltage

\section{Conclusion}

During the operation of the solar thermal system in the Department of Physics and Process Control, Szent István University, it was observed, that in case of weaker solar radiation the heat absorbed by the collectors, cannot get inside the solar tank due to the very long tubes because of the used on-off regulation.

The control system was modified, as the solar pump rotational frequency is regulated as the function of the temperature difference. For the modification a Labview routine was developed, which generates a temperature difference voltage to a frequency inverter, supplying the pump.

However some graph on the effect of the modification is presented, the energetic consequences of the modification is presented in a separate paper.

\section{Acknowledgements}

The authors would like to thanks the help of the Schneider Electric Hungária Villamossági Zrt for the free replacement of our faulted frequency regulator, and in this way supporting the research

\section{References}

[1.] Seres E. E., Farkas I., Biró A., Lágymányosi A., Buzás J.: 1998. Moduláris felépítésủ adatgyüjtő rendszer, MTA

[2.] Schneider Electric 2004. Altivar31 Installation Manual, Schneider Electric, 06/2004

[3.] Schneider Electric 2004. Altivar31 Programing Manual, Schneider Electric, 05/2004

[4.] National Instruments (2005): User Guide and Specifications USB6009, National instruments

[5.] John Essick (2015): Hands-On Introduction to Labview for Scientists and Engineers, Oxford University Press, 2015, ISBN: 978-0-19-992515-5 